\title{
RBEP
}

\section{A concepção dos professores e educadores de educação infantil sobre o saber de Morin: ensinar a condição humana}

Daniela Gureski Rodrigues

Daniele Saheb

http://dx.doi.org/10.1590/S2176-6681/337312857

\section{Resumo}

Tendo em vista que, devido à divisão do ensino em disciplinas, cada vez mais se fragmenta a visão do ser humano sobre si, assim, acredita-se que o ensino da condição humana deveria estar presente em todos os níveis de ensino, proporcionando aos indivíduos uma visão mais abrangente de si e do outro. Sob esse enfoque, este estudo pretende abordar e compreender as concepções que os professores e educadores de um Centro Municipal de Educação Infantil de Curitiba (PR) possuem sobre os aspectos que envolvem o terceiro saber de Morin: ensinar a condição humana. Portanto, foi necessário estabelecer as relações entre o terceiro saber, proposto por Morin, e as Diretrizes Curriculares Nacionais para a Educação Infantil de 2009, identificando-se aspectos presentes no discurso dos professores e educadores que revelem em sua atuação esse saber. Dessa maneira, sinalizam-se mudanças necessárias no que diz respeito à formação dos 
profissionais da educação infantil para que se desenvolva uma prática mais centrada na condição humana, e, assim, o indivíduo compreenda que faz parte de um todo, podendo, dessa forma, romper sua fragmentação.

Palavras-chave: condição humana; fragmentação; educação infantil; diferentes linguagens; Edgar Morin.

\section{Abstract \\ The conception of teachers and educators of early childhood education about the knowledge of Morin: teaching the human condition}

As a consequence of the teaching distributed into disciplines, the vision of human beings about themselves gets more fragmented. Therefore, it is believed that the teaching of the human condition should be present at all levels of education, in order to provide individuals with a broader vision about themselves and about others. Under this perspective, this study seeks to approach and comprehend some conceptions that teachers and educators of a Municipal Center of Early Childhood Education (Centro Municipal de Educação Infantil) of Curitiba, in the State of Paraná, have about the aspects that involve the third knowledge of Morin: teaching the human condition. Hence, it was necessary to establish relationships between the third knowledge of Morin and the National Curricular Guidelines for Early Childhood Education (Diretrizes Curriculares Nacionais para Educação Infantil) of 2009, and also, identify the aspects present in the discourse of teachers and educators that reveal that knowledge in their classroom practice. The results indicate that some changes are necessary in relation to the training of professionals of early childhood education, in order to develop a more focused practice in the human condition, so that individuals can realize that they are part of a whole and can, thus, break its fragmentation.

Keywords: human condition; early childhood education; different languages; Edgar Morin.

\section{Introdução}

A condição humana deveria ser objeto essencial em todo o ensino. Com a divisão das disciplinas e o formato de organização das instituições de ensino no Brasil, torna-se cada vez mais difícil apreender o que é o ser humano na sua totalidade. Por esse motivo, a educação tem a incumbência de buscar alternativas para que o indivíduo encontre seu lugar e se sinta parte do universo. 
O ensino da condição humana para Morin valoriza a diversidade, não consistindo apenas nos traços psicológicos, culturais e sociais, mas também no aspecto biológico. Para tanto, "compreender o humano é compreender sua unidade na diversidade, sua diversidade na unidade" (Morin, 2011, p. 50). Essa atitude apresenta, como consequência, o sentimento de reconhecimento das dimensões que simultaneamente constituem o ser humano: cósmica, física, biológica e cultural. Decorre daí a necessidade de um processo educativo que se desenvolva a partir da compreensão da relação hologramática e recursiva que nos constitui: indivíduo-espécie-sociedade.

Por ser a primeira etapa da educação básica, a educação infantil (EI) é de suma importância na formação do indivíduo. Segundo Morin (2001), partindo-se de uma formação integral da criança desde a primeira infância, o indivíduo pode desenvolver a capacidade de compreensão quanto a sua condição humana e suas dimensões.

Contudo, para que isso ocorra, mudanças no decorrer do processo de ensino e aprendizagem devem ser iniciadas desde a educação infantil, a fim de que, já na primeira etapa da educação básica, seja possível contribuir para a formação de indivíduos críticos e reflexivos, capazes de entender a globalidade e, principalmente, a si próprios e, depois, ao outro.

Com base nas reflexões apontadas, este artigo apresenta o resultado de uma pesquisa sobre o terceiro saber de Morin - ensinar a condição humana - no contexto da EI. Dessa forma, buscou-se investigar as concepções que os professores e educadores de um Centro Municipal de Educação Infantil (CMEI) de Curitiba (PR) possuem sobre os aspectos propostos por Morin em seu terceiro saber. Para tanto, foi realizada, inicialmente, pesquisa bibliográfica e documental com o intuito de estabelecer as relações entre o saber proposto por Morin e as Diretrizes Curriculares Nacionais para a Educação Infantil (DCNEI), fixadas pelo Conselho Nacional de Educação (Brasil. CNE, 2009). Em seguida, a pesquisa de campo envolveu oito sujeitos, sendo seis educadores e dois professores, tendo como objetivo identificar aspectos referentes ao ensino da condição humana no discurso dos professores e educadores.

A análise e a discussão dos dados obtidos por meio das entrevistas revelaram que, apesar de os professores/educadores buscarem desenvolver um trabalho que engloba muito do que diz respeito ao ensino da condição humana, ainda há necessidade de mudança na prática docente. Acredita-se que essa reestruturação tenha que partir da formação dos professores que irão atuar nos diferentes níveis de ensino, pois só assim será possível alcançar a tão almejada mudança na educação.

A formação de professores é um ponto primordial concernente à mudança na educação; propostas quanto à formação desses profissionais já vêm sendo discutidas há vários anos e sofrendo inúmeras reformulações. No que diz respeito à formação dos profissionais que atuam na educação infantil, ainda se acredita em evolução e melhorias. Dessa maneira, é necessária uma reflexão sobre a complexidade do processo de ensino e aprendizagem e sobre a necessidade de superar sua fragmentação na prática pedagógica, para que, assim, possamos superar métodos defasados e modelos reducionistas de ensino. 


\section{Formação dos profissionais da educação infantil}

Segundo o Referencial Curricular Nacional para a Educação Infantil (RCNEI), estudos apontam que a maioria dos profissionais que atuam na EI não possui formação adequada. Assim, faz-se necessária a possibilidade de atualização profissional e uma nova formação que corresponda às demandas atuais, pois acredita-se na necessidade de uma formação mais abrangente e unificadora (Brasil. MEC. SEF, 1998).

Diante dessa discussão, a Lei de Diretrizes e Bases da Educação Nacional (LDB) traz, em seu artigo 62, a necessidade da formação desses profissionais (Brasil, 1996). Ao encontro da LDB cita-se, ainda, a Resolução CNE/CEB no 4, de 13 de julho de 2010, que destaca, em seu artigo 57, a importância da formação continuada, ressaltando que esta se associa à garantia da qualidade e à valorização do profissional da educação.

Cabe destacar que ser professor não é apenas obter diplomas e uma gama de técnicas; é necessário que se obtenha uma formação reflexiva. Como destaca Nóvoa (1995, p. 25):

a formação não se constrói por acumulação (de cursos, de conhecimentos ou de técnicas), mas sim através de um trabalho de reflexividade crítica sobre as práticas e de (re)construção permanente de uma identidade pessoal. Por isso é tão importante investir na pessoa e dar um estatuto ao saber da experiência.

Contudo, ainda prevalece, em alto índice, a formação profissional reducionista, suscitando a preferência por métodos defasados, que não permitem que o aluno desenvolva seu lado crítico. Essas situações acontecem pela ausência de pesquisa por parte dos professores, os quais não buscam estabelecer relação entre os conteúdos e o cotidiano dos seus alunos, tornando o ensino fragmentado e fazendo com que os aprendentes não tenham um olhar abrangente.

Segundo Moraes e Navas (2010, p. 176), "o pensamento ecossistêmico, fundamentado na complexidade, exige o repensar a docência de um modo mais articulado, integrado e competente". Para tanto, é necessária a reflexão do trabalho docente existente hoje, juntamente com o projeto das mudanças ainda necessárias, para que, a partir da formação de professores, se possa promover uma reforma no pensamento, e, assim, haja uma reforma na educação, como propõe Morin.

Acreditando que as pequenas partes afetam o todo, se a formação docente tiver um viés para a complexidade, mudanças significativas ocorrerão em todo o processo, pois, alcançando a formação de excelentes professores, outros processos serão afetados diretamente, atingindo os demais profissionais. Para Moraes e Navas (2010, p.179):

na realidade, nossas escolas necessitam de professores capazes de organizarem ambientes agradáveis e efetivos de aprendizagem, ambientes prazerosos e implicativos, onde os alunos sintam-se acolhidos e nutridos no seu sentido mais amplo. 
Logo, chega-se a um parâmetro segundo o qual é possível pensar que esses docentes necessitam de uma formação que não seja fragmentada, mas que busque desfragmentar o ensino, articulando o conhecimento com a realidade vivenciada, aprendendo a trabalhar com o erro e com a incerteza, procurando a compreensão e buscando, dessa maneira, uma visão do todo. Segundo Moraes e Navas (2010, p.184):

\begin{abstract}
é a complexidade que nos ajuda a melhor compreender e explicar a realidade educacional, esclarecendo-nos que esta não é apenas feita de racionalidade e de fragmentação mas também de processos intuitivos, emocionais, imaginativos e sensíveis. Isto porque, nós, seres humanos, somos também feitos de poesia e de prosa, de emoção, de sentimento, de intuição e de razão, e tudo isto, orgânica e estruturalmente, é articulado em nossa corporeidade.
\end{abstract}

Assim, é preciso que os formadores não englobem, no processo educacional, apenas exercícios referentes aos conteúdos, mas possam integrar em suas aulas momentos que levem o indivíduo a refletir sobre si e sobre o outro, a trabalhar com sua emoção, com seus sentimentos e, ao mesmo tempo, a considerar a intuição, e não apenas a racionalidade. Dessa maneira, é essencial que se busquem essas mudanças e se repense a formação de professores de uma forma mais articulada, desvinculando-se, quando necessário, do tradicionalismo que tanto subsidia o trabalho docente.

\title{
Os sete saberes
}

Edgar Morin escreveu o livro Os sete saberes necessários à educação do futuro, em 1999, a pedido da Organização das Nações Unidas para a Educação, a Ciência e a Cultura (Unesco). O livro tem por finalidade chamar a atenção dos educadores para uma nova percepção da educação do século 21, para um ensino centrado na condição humana. O texto de Morin, porém, não é um manual com regras a serem seguidas, mas tem como objetivo levar o educador a rever suas práticas e redefinir sua posição perante os seus alunos, o currículo, as disciplinas, entre outros.

Morin ([1999] 2001) se refere aos sete saberes como os sete buracos negros da educação, que são os pontos da discussão sobre o que se faz necessário para ensinar no século 21 - as cegueiras do conhecimento: o erro e a ilusão; os princípios do conhecimento pertinente; o ensino da condição humana; o ensino da identidade terrena; o enfrentamento das incertezas; o ensino da compreensão; e a ética do gênero humano.

Diante dos sete saberes propostos por Morin (2001), optou-se, nesta pesquisa, por evidenciar o terceiro saber - ensinar a condição humana -, pois se acredita que o ser humano é o objeto essencial dos demais saberes, posto que, em todos os saberes, é necessário que o indivíduo mude sua posição considerando diferentes aspectos. Contudo, isso não pode ocorrer se ele não obtiver a condição humana que o identifique como ser humano e como parte do universo. Assim, compreende-se que esse saber é o mais completo, pois engloba todos os demais. 


\section{A relação entre o terceiro saber e as Diretrizes Curriculares Nacionais para a Educação Infantil, de 2009}

Considerando que a EI e o terceiro saber são o foco da pesquisa, cabe, neste momento, uma reflexão sobre as relações que foram estabelecidas entre o terceiro saber de Morin (2001) e as DCNEI, fixadas pela Resolução CNE/CEB n ${ }^{\circ}$ 5, de 17 de dezembro de 2009, para orientar o trabalho nas instituições que atuam com esse nível educacional. O objetivo das Diretrizes é o desenvolvimento integral da criança e a melhoria da estruturação e da organização das ações desenvolvidas na educação infantil, norteando o trabalho a ser realizado com a criança de zero a cinco anos, definida como:

Sujeito histórico e de direitos que, nas relações e práticas cotidianas que vivencia, constrói sua identidade pessoal e coletiva, brinca, imagina, fantasia, deseja, aprende, observa, experimenta, narra, questiona e constrói sentidos sobre a natureza e a sociedade, produzindo cultura. (Brasil. CNE, 2009, p. 1).

A criança pensa sobre o mundo e atribui sentido ao que lhe é oferecido, sem passar intacta ao que lhe oferecem na instituição de educação infantil. Assim, as DCNEI propõem que o currículo da educação infantil tenha como eixos norteadores as interações e as brincadeiras, mas garantindo diversas experiências, como o conhecimento de si e do mundo, a imersão das crianças em diferentes linguagens, o conhecimento, o respeito à diversidade cultural, entre outras.

A educação do futuro deverá ser o ensino primeiro e universal na condição humana. Estamos na era planetária; uma aventura comum conduz os seres humanos, onde quer que se encontrem. Estes devem reconhecer-se em sua humanidade comum e, ao mesmo tempo, reconhecer a diversidade cultural inerente a tudo que é humano. (Morin, 2001, p. 43).

O contato da criança com as outras e com os profissionais que trabalham nas instituições de educação infantil as auxilia na construção de sua cultura. Do mesmo modo, as experiências que vivencia nessa fase levam-na a reconhecer-se na humanidade e a reconhecer a diversidade cultural ao seu redor. Morin (2001, p.51) afirma que:

A cultura é constituída pelo conjunto dos saberes, dos fazeres, das regras, das normas, das proibições, das estratégias, das crenças, das ideias, dos valores, dos mitos, que se transmite de geração em geração, se reproduz em cada indivíduo, controla a existência da sociedade e mantém a complexidade psicológica e social.

Isso também pode ser encontrado nas DCNEI, segundo as quais as práticas pedagógicas devem garantir experiências que: "possibilitem vivências éticas e estéticas com outras crianças e grupos culturais, que alarguem seus padrões de referência e de identidades no diálogo e reconhecimento da diversidade" (Brasil. CNE, 2009, p. 4). 
Afirma-se, assim, uma relação entre o que Morin apresenta sobre a cultura do indivíduo, que é constituída por um conjunto e que vai sendo transmitida de geração em geração, e a cultura do outro, haja vista a importância de que o indivíduo conheça e respeite a cultura e a diversidade do outro para que se obtenha a condição humana.

As Diretrizes fazem referência ainda a questões ambientais, as quais devem ser trabalhadas na EI, assim como a Lei $\mathrm{n}^{\circ}$ 9.795, de 27 de abril de 1999, que, em seu artigo 9º, estabelece que a educação ambiental deve ser desenvolvida no âmbito dos currículos escolares, englobando todos os níveis de ensino, inclusive a EI. As DCNEI apontam que as experiências pedagógicas devem promover "a interação, o cuidado, a preservação e o conhecimento da biodiversidade e da sustentabilidade da vida na Terra, assim como o não desperdício dos recursos naturais" (Brasil. CNE, 2009, p. 4). Morin (2011, p. 44) afirma que:

Disso decorre que, para a educação do futuro, é necessário promover grande remembramento dos conhecimentos oriundos das ciências naturais, a fim de situar a condição humana no mundo, dos conhecimentos derivados das ciências humanas para colocar em evidência a multidimensionalidade e a complexidade humanas, bem como integrar (na educação do futuro) a contribuição inestimável das humanidades, não somente a filosofia e a história, mas também a literatura, a poesia, as artes [...]

É necessário que, na educação infantil e em todos os outros níveis escolares, haja uma ótica que inclua a educação ambiental, pois, o ser humano, conhecendo as ciências naturais, integrando-se na natureza e na humanidade e reconhecendo-se como parte da sociedade, inicia a constituição da sua condição humana.

Para que todo esse processo ocorra, é necessário que haja um ensino centrado na condição humana, que não seja fragmentado, pois, como Morin (2001) aponta, a compartimentação das disciplinas contribui para que o indivíduo venha a ter dificuldade em globalizar, ou seja, em ver o todo. Verdade essa que acarreta a individualidade do ser humano e acaba por se tornar uma inteligência blindada e sem o potencial de ser multidimensional.

\section{Resultados}

A presente pesquisa foi realizada em um Centro Municipal de Educação Infantil, na cidade de Curitiba (PR), onde a base do trabalho é o cuidar e o educar alicerçado em brincadeiras, buscando desenvolver a autonomia das crianças. Foram entrevistados professores e educadores de crianças entre dois e cinco anos de idade. O cargo de educador da Prefeitura Municipal de Curitiba é destinado a profissionais na EI com carga horária de 40h semanais, sendo exigida a formação mínima do ensino médio na modalidade normal (magistério) ou subsequente na modalidade normal (magistério). 
Optou-se pela entrevista como procedimento de pesquisa, que foi utilizada tendo por objetivo a obtenção de dados descritivos que partiriam do próprio sujeito investigado, permitindo uma melhor interpretação do investigador. As questões focalizaram os seguintes aspectos: concepção de criança; objetivo da educação infantil; concepção de diversidade; natureza e sociedade; e diferentes linguagens. Isso se justifica devido ao fato de que o ensino da condição humana para Morin corresponde, entre outros aspectos, às concepções que os sujeitos possuem sobre si e sobre o outro.

Os seres humanos devem reconhecer-se em sua humanidade comum e, ao mesmo tempo, reconhecer a sua diversidade cultural, mas, para que isso ocorra, se faz necessário o ensino da pintura, da literatura, do cinema, da música, pois, para Morin (2011, p. 45), "em toda grande obra... há um pensamento profundo sobre a condição humana". Entende-se, assim, que as questões apontadas podem contribuir para que seja possível identificar aspectos convergentes com o ensino da condição humana de Morin nas falas dos educadores e professores.

\section{Percepções dos participantes sobre a definição de criança}

A concepção de criança é algo que vem sendo construída historicamente e que passou por grandes contrastes no decorrer da história. Percorreu-se um longo caminho para que se chegasse ao que hoje se aponta como uma "definição" adequada de criança.

As DCNEI (Brasil. CNE, 2009) definem a criança como um sujeito histórico, de direitos e produtor de cultura diante de suas interações. No entanto, as falas dos entrevistados demonstraram uma concepção assistencialista, visto que estes acreditam que a criança é um sujeito indefeso e que precisa de cuidados, sem mencionar a necessidade do desenvolvimento da autonomia na EI. As falas a seguir comprovam a concepção assistencialista que alguns educadores possuem:

É um ser indefeso que precisa de cuidados, é igual uma pessoa idosa, necessita do maior cuidado, depende tudo da gente e o futuro da gente está aí com as nossas crianças. (E1).

Um ser em desenvolvimento, que precisa de cuidados. (E4).

Além da visão assistencialista, alguns professores/educadores possuem ainda uma visão romântica de que a criança é um ser indefeso e que precisa constantemente do cuidado dos adultos. Contudo, sabe-se que, desde a LDB (Brasil, 1996), as instituições de EI não devem mais possuir um cunho assistencialista, visto que o desenvolvimento integral da criança, segundo Oliveira (2002), foi uma grande conquista.

Alguns professores/educadores possuem uma visão diferenciada no que diz respeito à definição de criança, a qual se aproxima mais da concepção que perdura atualmente, definindo-a como um ser em desenvolvimento e respeitando suas especificidades: 
É um sujeito social, histórico, que está em um processo de desenvolvimento, mas que possui conhecimento, ao mesmo tempo é um ser lúdico que faz suas próprias construções, toma suas próprias decisões e precisa da intervenção de um adulto a todo momento. (P1).

Podem ser destacadas, em uma das falas, questões relacionadas ao planejamento, quando a entrevistada destaca a importância de conhecer seus alunos para depois preparar seu planejamento, acentuando que as crianças não são tábulas rasas como se pensava no século 16, mas já chegam à educação infantil com diversos conhecimentos, os quais devem ser aproveitados e ampliados pelos docentes.

É um ser lúdico, único, que a gente precisa conhecer primeiro pra depois imaginar o que planejar, pra poder chegar e alcançar a cabecinha de cada um. Um serzinho único que não é vazio como muita gente acha, que todo o conteúdo, a cultura da casa já vem com ele, absorve tudo, tem uma antena que capta tudo. (E2).

É possível destacar o papel interventor que os adultos possuem na formação desses indivíduos. Apesar de o cuidado estar atrelado à educação infantil, ele não é o fator preponderante em algumas práticas que buscam aliar o conhecimento que o indivíduo já possui e seus interesses ao planejamento, procurando, dessa forma, o desenvolvimento integral da criança.

\section{Percepções dos participantes sobre o objetivo da educação infantil}

A EI é definida nas DCNEI como a primeira etapa da educação básica, constituindo-se de espaços educacionais que oferecem cuidado e educação a crianças de dois a cinco anos. Destacamos as falas de alguns sujeitos que vão ao encontro do que propõem as Diretrizes:

Eu acho que o primordial é auxiliar no desenvolvimento, mostrar as possibilidades que eles podem, o que eles podem fazer, aonde eles podem chegar. Acho que esse é o nosso papel, mas, como eu já disse, de uma forma lúdica, brincando. (E2).

Acho que é principalmente ajudar no desenvolvimento psicológico, intelectual e social da criança e nós somos responsáveis por isso, responsáveis por fazer atividades que levem essa criança a esse desenvolvimento. (P2).

Acentua-se nas falas desses sujeitos a importância de propiciar às crianças diferentes maneiras de ampliar seu desenvolvimento, garantindo que tenham a oportunidade de experimentar várias situações que contribuam para a construção da sua autonomia. Segundo Kramer (1995, p.76):

Do meu ponto de vista, não é possível educar sem cuidar [...] Há atividades que uma criança pequena não faz sozinha e são atividades básicas de cuidado, que garantem sua sobrevivência. Ou seja, há atividades de 
cuidado que são específicas da educação infantil, contudo, no processo de educação, em qualquer nível de ensino, cuidamos sempre do outro. Ou deveríamos cuidar! [...] já não será hora de assumir o educar, entendendo que abrange as duas dimensões.

Vale ressaltar a importância dos profissionais que atuam nas instituições de EI para exercitar a consciência de que essas duas práticas - cuidar e educar - são indissociáveis, no entanto, ao mesmo tempo em que alguns docentes se destacam pela importância que dão ao cunho pedagógico, alguns com mais anos de experiência, e até por fazerem parte da rede municipal, destacam que compreendem a mudança, mas ainda não conseguiram modificar seu olhar para as crianças, acreditando que estas estão na instituição apenas para serem cuidadas enquanto seus pais trabalham.

A educação infantil é isso, se você não tiver, como eles vão para a escola? Aonde que eles vão ficar? Vão ficar na rua? E a mãe, como vai trabalhar e deixar essa criança em casa sozinha? Então a educação infantil precisa existir. (E1).

Mesmo a educação infantil tendo passado por um grande processo de transformação no que diz respeito ao cuidar e ao educar, ainda existem profissionais que possuem uma visão limitada quanto à formação das crianças. Esses profissionais são os mesmos que apontam a criança como um ser indefeso, tendo a EI com um cunho assistencialista.

Alguns pontos precisam ser repensados pelos docentes que atuam nas instituições de EI, pois, para que haja uma prática efetiva que contribua para o desenvolvimento integral das crianças, é preciso que os professores sejam conscientes do papel que desempenham e da importância de deixar de lado o cunho assistencialista, para que, assim, possam assumir o papel de sujeitos produtores de cultura.

Percepções dos participantes sobre as diferentes linguagens para aprendizagem

A educação infantil é o espaço que deve propiciar às crianças diferentes experiências, buscando levá-las a desenvolver sua formação integral, como destaca a LDB em seu artigo 29:

A educação infantil, primeira etapa da educação básica, tem como finalidade o desenvolvimento integral da criança até seis anos de idade, em seus aspectos físico, psicológico, intelectual e social, complementando a ação da família e da comunidade. (Brasil, 1996, p. 12).

Para que isso aconteça de maneira efetiva, ressalta-se, ainda, o que dispõem as DCNEI sobre as práticas pedagógicas que compõem a proposta da educação infantil, as quais devem garantir aos indivíduos experiências que: 
favoreçam a imersão das crianças nas diferentes linguagens e o progressivo domínio por elas de vários gêneros e formas de expressão: gestual, verbal, plástica, dramática e musical.

\section{$[\ldots]$}

promovam o relacionamento e a interação das crianças com diversificadas manifestações de música, artes plásticas e gráficas, cinema, fotografia, dança, teatro, poesia e literatura. (Brasil. CNE, 2009, p. 4).

Os docentes precisam, portanto, contemplar em seus planejamentos a utilização das diferentes linguagens e, nas suas falas, todos buscam propiciar experiências para as crianças, não por considerarem que são importantes, mas por ser a proposta da rede e por alguém exigir a realização desse trabalho, como comprovam as falas a seguir:

Trabalha, alguma coisa a gente sempre trabalha. A oralidade... a gente faz roda de conversa todo dia. É obrigado, tem que fazer. Aí tem o movimento que também tem que trabalhar todo dia e a pedagoga, aqui, ela cobra bastante. (E3).

Sim, acho que consigo trabalhar todas, pelo menos eu tento, até porque é a proposta da rede. Oralidade a gente tem a roda de conversa todo dia, canta música, teatro é da permanência, eu não trabalho, movimento é trabalhado todos os dias através de brincadeiras, circuitos, acho que é isso. (P2).

No entanto, alguns professores acreditam que o trabalho com as diferentes linguagens é de extrema importância, contribuindo para a formação dos indivíduos.

Utilizo todas. No começo a gente faz um planejamento anual e ali a gente põe uma ideia do que a gente tem já com a relação à idade que eles estão, mas com o decorrer dos dias a gente vai vendo as necessidades deles, o que eles gostam mais. A gente tem um momento de roda de música, pra gente aprender com ritmo e tal, porque música sozinha, sem movimento não existe. (E2).

Sim, todas, eu procuro sempre trabalhar com projetos, então eu divido as linguagens e foco cada projeto em uma específica, claro que todos abordam um pouco de cada linguagem, mas foco sempre em uma. Por exemplo, eu fiz um projeto pra trabalhar a linguagem musical, então eles pesquisaram músicas com os pais, instrumentos que os pais tocam. (P1).

Esses docentes relatam maneiras de inserir as diferentes linguagens em suas práticas e percebe-se que não as utilizam apenas por fazer parte da proposta, mas por acreditarem que estas auxiliam de maneira efetiva no desenvolvimento das crianças, destacando ainda que a brincadeira, que é um dos eixos norteadores propostos pelas DCNEI, não pode ser esquecida em nenhum momento. Para Morin (2011, p.45):

As artes levam-nos à dimensão estética da existência e - conforme o adágio que diz que a natureza imita a obra de arte - elas nos ensinam a ver o mundo esteticamente. Trata-se, enfim de demonstrar que, em toda obra, de literatura, de cinema, de poesia, de música, de pintura, de escultura, há um pensamento profundo sobre a condição humana. 
Com isso, pode-se afirmar que alguns desses sujeitos propiciam às crianças o contato com diversas possibilidades de ampliação de experiências, como a música, a dança, a poesia, entre outros, levando esses indivíduos a trabalharem não apenas com questões racionais, mas com o que diz respeito ao emocional e à afetividade, que fazem parte da condição humana.

Percepções dos participantes sobre trabalho com a diversidade

Quanto à diversidade, as DCNEI destacam que as instituições de EI devem assegurar:

O reconhecimento e a valorização, o respeito e a interação das crianças com as histórias e as culturas africanas, afro-brasileiras, bem como o combate ao racismo e à discriminação. (Brasil. CNE, 2009, p. 3).

Assim, deveria ser propiciado às crianças momentos de interação, de diálogo, de brincadeiras, que enriqueçam seu conhecimento sobre a diversidade, porém, nota-se uma grande dificuldade por parte dos docentes em trabalhar com essa área.

Não é muito trabalhado, não. Eu acho importante porque é a fase deles que eles aprendem mais, então tudo que você aplica é importante. Então porque você não trabalha muito? Sinceramente, por não saber como trabalhar essas questões com eles, por eles serem tão pequenos, acredito que não vão compreender. (E1).

Voltando à concepção de criança, esses mesmos docentes são os que afirmam que se trata de um ser que necessita de cuidados, o que pode ser um fator de interferência em sua concepção sobre o aprendizado das crianças, de modo que passam a acreditar que estas não estão aptas a compreender a diversidade por não terem maturidade.

Apesar de algumas concepções ultrapassadas citadas anteriormente, alguns docentes compreendem que o trabalho com a diversidade é de suma importância para as crianças e buscam propiciar momentos que ampliem seus padrões de referência, assim como proposto nas DCNEI.

Sim, eu procuro mostrar pra eles que existe pessoas diferentes, por exemplo, deficientes, de cor, famílias diferentes e que eles têm os mesmos direitos que nós, que podem fazer tudo o que nós podemos fazer. E como você faz isso? Mostro filmes, fazemos pesquisas, fizemos os mascotes da sala, um com bengala, um de óculos e um negro, pra justamente trabalhar essas questões. (P2).

Ainda nesse aspecto, a docente P1 destaca um projeto realizado, no qual, além de apontar o uso das diferentes linguagens, ressalta a relevância de se trabalhar essas questões com as crianças.

Sim, acho extremamente importante, pois eles precisam conhecer tudo, precisam ter uma base, as crianças não podem ser alheiạ às coisas do mundo. Eu fiz um projeto semestre passado sobre a África e eles adoraram, eles exploraram, fizeram pesquisa em revista, computador, 
assistiram filmes, eles precisam conhecer tudo e, além disso, respeitar, pois vão encontrar muita diferença no mundo e não podem excluir e nem se sentir excluídos por serem diferentes. (P1).

Já a educadora E4 evidencia como realiza o trabalho em sala de aula, compartilhando a experiência de ter um aluno de inclusão.

\begin{abstract}
A gente não explica, assim como pra um adulto, no caso o A (síndrome de down) e o E (negro), a gente não fala "esse é assim, esse é assado", a gente procura não incluir eles em um grupo, as crianças escolhem eles por si próprias. E não é assim, hoje nós vamos falar sobre o negro, o que é o negro? Não, não é assim, a gente simplesmente conversa com eles que todos são iguais, só que a gente não fala que um tem uma síndrome e o outro é de cor, a gente fala que existem diferenças entre todos, mas que somos iguais, entende? (E4).
\end{abstract}

Ela destaca ainda a importância de se dar autonomia para que as crianças escolham seus parceiros para brincar, sem necessidade de imposição. Aponta ainda que procura fazer com que as crianças compreendam que não há diferença quanto a direitos e possibilidades. Já a educadora E2 destaca ainda a importância dessa dimensão para a formação do caráter desses indivíduos:

Trabalho, acho que em tudo que a gente faz durante o dia a gente já está trabalhando com a diversidade em tudo, na hora de uma contação, na hora de uma brincadeira, na hora de uma alimentação, acho que a gente sempre vai colocando os pontos positivos, sempre incentivando, nunca bloqueando, e incentivando eles a se abrirem pra tudo. Eu acho muito importante, porque agora que a gente vai formar o caráter deles, a gente vai auxiliar nessa formação de caráter, até eles chegarem nos cinco, sete anos, se eles não tiverem isso prontinho, já era. (E2).

Para Morin (2001, p.50):

É a unidade humana que traz em si os princípios de suas múltiplas diversidades. Compreender o humano é çompreender sua unidade na diversidade, sua diversidade na unidade. E preciso conceber a unidade do múltiplo, a multiplicidade do uno.

Em alguns desses docentes é possível verificar a realização do trabalho com a diversidade, não deixando de lado a unidade de cada um, o que, segundo Morin, é de suma importância, posto que um é complemento do outro. Por isso, é imprescindível que os docentes trabalhem com as questões da diversidade, independentemente do nível de ensino em que atuam.

Percepções dos participantes sobre a área do conhecimento natureza e sociedade

Em relação ao que as DCNEI apresentam sobre as questões da natureza, afirma-se que devem ser garantidas aos indivíduos que frequentam as instituições de EI experiências que promovam "a interação, o cuidado, a preservação e o conhecimento da biodiversidade e da sustentabilidade da vida na Terra [...]" (Brasil. CNE, 2009, p. 4). 
Na visão de Morin (2011, p. 31), "conhecer o humano não é separá-lo do universo, mas situá-lo nele". No que diz respeito às questões da natureza, os docentes julgam importante trabalhá-las com as crianças, buscando promover experiências significativas nas quais elas possam estar em contato com o meio natural. Isso pode ser visto nas respostas dos entrevistados:

Nas questões da natureza é feito horta, andamos pelo CMEI, explicamos sobre a natureza, a terra, o sol, essas questões, o que é flor, o que é arvore frutífera. (E1).

Referente à natureza, é importante eles conhecerem porque hoje em dia a gente foca muito o papel, o material, dentro de sala, e a parte do trabalho com a natureza, a gente esquece muito, então, eu acho importante mostrar pra eles como que nasce uma plantinha, como que ela se desenvolve, trabalhar isso, montar uma horta, levar eles para ver os animais, conhecer pelo menos. (E5).

Pode-se perceber, a partir da fala dos docentes, que estes buscam desenvolver valores ambientais nas crianças, partindo de interações que ampliem as experiências destas e buscando promover o conhecimento da biodiversidade e da sustentabilidade. Pode ser destacado, ainda, na fala da educadora E2, um planejamento enriquecido que busca ampliar a visão das crianças, não apenas para o que está em foco naquele momento em sala, mas para tudo que desperta o interesse nelas.

Aqui nessa fase a gente trabalha a identidade deles, de onde eles vieram, como eles são, daí a gente já trabalha a diversidade, as diferenças, a gente busca um planejamento que eles tenham contato com a natureza, aprendam a respeitar a natureza, mas brincando. A gente tá na hora da escovação, na hora de procurar os bichinhos lá fora, dizer a importância daquilo, de conhecer o bairro onde eles moram, de conhecer o que existe aqui. (E2).

Destaca-se ainda nessa fala a integração que a educadora promove entre natureza e sociedade, pois, ao mesmo tempo que busca trabalhar as questões de convivência e as questões de diversidade com as crianças, ela inclui as questões da natureza, o que é essencial para se viver em sociedade, respeitar os demais indivíduos e respeitar o planeta.

Contudo, uma das docentes afirma que, apesar de trabalhar com as questões ambientais, não acredita na eficácia desse trabalho:

Olha, natureza é bem mais complicado de trabalhar, pois nem a gente tem essas questões de cuidar e preservar internalizadas em nós. Então eu me pergunto como fazer isso com as crianças, eu tento fazendo horta, mostrando pra eles o que acontece quando jogamos lixo no chão ou não fechamos a torneira. Mostro vídeos, fazemos cartazes, mas não sei se funciona. (P2).

Assim, pode-se afirmar que, apesar de alguns docentes não acreditarem que esse trabalho possa dar resultado, nenhum deles deixa de trabalhar questões referentes à natureza.

Em relação às questões da sociedade, os docentes destacam a brincadeira como fio condutor para que os indivíduos aprendam a conviver 
melhor entre si, a se respeitar e a compreender as regras, pois acreditam que as vivências no CMEI são aprendizagens para a vida adulta.

Sim, pois é muito válido, criança tem que ter conhecimento da sociedade, porque aqui e aonde for, a vida toda ela vai tá no meio de gente. E como você procura trabalhar isso? Brincando, dividindo brinquedos, interagindo entre elas. (E1).

Referente à sociedade, talvez trazendo assim as regras, porque querendo ou não, eles têm algumas regrinhas que a gente desenvolve com eles aqui dentro do CMEI que futuramente vão servir pra vida deles, porque aqui é a base. (E5).

Contudo, percebe-se uma dificuldade dos docentes em compreender que as questões relacionadas à natureza e à sociedade estão interligadas. Mesmo que em suas falas se possa perceber um trabalho simultâneo entre essas áreas do conhecimento, ao serem questionadas sobre o trabalho, as docentes relatam essas práticas como se fossem dissociadas.

De fato, os docentes buscam realizar um trabalho que valorize a natureza e a sociedade e, mesmo que inconscientemente, unem ambas ao desenvolver suas práticas com as crianças, levando-as a interagir entre si, promovendo o respeito mútuo e integrando o respeito à natureza a essas práticas, o que se aproxima do pensamento de Morin.

\section{Considerações finais}

A presente pesquisa teve como objetivo investigar as concepções que os professores e educadores de um Centro Municipal de Educação Infantil de Curitiba possuem sobre o terceiro saber de Morin: ensinar a condição humana. De acordo com o enfoque do trabalho, utilizou-se a metodologia qualitativa, usando como instrumento a entrevista, a qual possibilitou identificar os aspectos presentes no discurso dos professores e educadores que se direcionavam ao terceiro saber de Morin (2001).

A análise dos dados revelou que ainda existe entre os educadores uma visão assistencialista a respeito da criança, sendo esta caracterizada como um ser indefeso. Essa concepção foi reforçada pelas falas das quais se depreende que o objetivo principal da EI é cuidar das crianças enquanto seus pais trabalham. No entanto, percebeu-se entre os sujeitos da pesquisa, ainda que de forma embrionária, a compreensão acerca da articulação das DCNEI com a qualidade do processo de ensino e aprendizagem da criança da EI.

A diversidade foi o aspecto de maior objeção entre todos os entrevistados, pois a maioria ressaltou não saber como trabalhá-lo pela falta de conhecimento, e os que citaram desenvolvê-lo evidenciaram a dificuldade de trabalhar com o tema, e, mesmo quando é abordado em sala de aula, é trabalhado de maneira superficial.

Outro aspecto destacado foi a concepção de natureza e sociedade, compreendidas pelos entrevistados como dimensões independentes e que não se relacionam. 
O aspecto mais dialogado neste trabalho foram as diferentes linguagens, talvez por ser uma das bases do trabalho da EI na Prefeitura Municipal de Curitiba. Os entrevistados expressaram obter conhecimento sobre o assunto, disseram que são exigidos em relação a esse trabalho, uma vez que as linguagens devem ser apresentadas todos os dias de diferentes maneiras, buscando a contemplação de todas durante a semana.

Constatou-se, por meio deste estudo, que a abordagem realizada por Morin sobre a condição humana pode ser relacionada a muitos aspectos das DCNEI, como: a importância de o ser humano conhecer suas individualidades, se relacionar com o outro, produzir e conhecer outras culturas, trabalhar questões voltadas à diversidade, à natureza e aos demais aspectos essenciais para o seu desenvolvimento. Esses aspectos puderam ser observados no discurso de alguns educadores/professores, ainda que de maneira superficial.

Verificou-se que um percentual significativo de professores/educadores busca desenvolver um trabalho que vá ao encontro das DCNEI, com o ideal de inserir, por exemplo, filmes, músicas e teatro com o objetivo de trabalhar as diferentes linguagens. Mas, mesmo que o trabalho seja efetivado, a maior parte dos profissionais aponta ter dificuldade em abordar alguns temas com as crianças, por falta de conhecimento teórico e/ou metodológico.

Por essa razão, pode-se dizer que, mesmo de maneira involuntária, a condição humana, ou seja, o terceiro saber de Morin, é encontrada em algumas das concepções dos profissionais pesquisados. Porém, para que isso se consolide na EI, é preciso pensar na formação dos profissionais que irão atuar junto a essas crianças.

Então, para ocorrer um ensino centrado na condição humana dentro da EI, é necessário que, primeiramente, a mudança aconteça na formação desses profissionais, de modo a privilegiar o conhecimento sobre si e sobre o mundo, sem fragmentar o indivíduo. Assim, o modo de ensinar será transformado em um processo que se refletirá nas demais etapas da educação.

\section{Referências bibliográficas}

AlMEIDA, Maria da Conceição de; CARVAlHO, Edgard de Assis.

Educação e complexidade: os sete saberes e outros ensaios. São Paulo: Cortez, 2002.

BOGDAN, Robert C.; BIKLEN, Sari Knopp. Investigação qualitativa em educação: uma introdução à teoria e aos métodos. Porto: Porto Ed., 1994. 
BRASIL. Lei no 9.394, de 20 de dezembro de 1996. Estabelece as diretrizes e bases da educação nacional. Diário Oficial da União, Brasília, DF, 23 dez. 1996. Disponível em: <http://www.planalto.gov.br/ccivil_03/ leis/19394.htm>.

BRASIL. Lei no 9.795, de 27 de abril de 1999. Dispõe sobre a educação ambiental, institui a Política Nacional de Educação Ambiental e dá outras providências. Diário Oficial da União, Brasília, DF, 28 abr. 1999. Disponível em: <http://www.planalto.gov.br/ccivil_03/leis/19795.htm>.

BRASIL. Conselho Nacional de Educação (CNE). Câmara de Educação Básica (CEB). Resolução no 4, de 13 de julho de 2010. Define Diretrizes Curriculares Nacionais Gerais para a Educação Básica. Diário Oficial da União, Brasília, DF, 14 jul. 2010. Seção 1, p. 824. Disponível em: <http:// portal.mec.gov.br/dmdocuments/rceb004_09.pdf >

BRASIL. Conselho Nacional de Educação (CNE). Câmara de Educação Básica (CEB). Resolução no 5, de 17 de dezembro de 2009. Fixa as Diretrizes Curriculares Nacionais para a Educação Infantil. Diário Oficial da União, Brasília, DF, 18 dez. 2009. Seção 1, p. 18. Disponível em: $<$ http://portal.mec.gov.br/index.php?option $=$ com_docman\&task $=$ doc download\&gid $=9769 \&$ Itemid $>$.

BRASIL. Ministério da Educação (MEC). Secretaria de Educação Básica (SEB). Diretrizes curriculares nacionais para a educação infantil. Brasília, DF, 2010. $36 \mathrm{p}$.

BRASIL. Ministério da Educação (MEC). Secretaria de Educação Fundamental (SEF). Referencial Curricular Nacional da Educação Infantil [RCNEI]. Brasília, DF, 1998.

KRAMER. Sônia. A política do pré-escolar no Brasil: a arte do disfarce. Rio de Janeiro: Achime, 1995.

LOCKE, John. Ensaio acerca do entendimento humano. São Paulo: Nova Cultural, 2009.

MORAES, Maria Cândida; ALMEIDA, Maria da Conceição de. Os sete saberes necessários à educação do presente: por uma educação transformadora. Rio de Janeiro: Wak, 2012.

MORAES, Maria Cândida; NAVAS, Juan Miguel (Org.). Complexidade e transdisciplinaridade em educação: teoria e prática docente. Rio de Janeiro: Wak, 2010. 
MORIN, Edgar. A cabeça bem feita. Rio de Janeiro: Bertrand Brasil, 2011.

MORIN, Edgar. Os sete saberes necessários à educação do futuro. 2. ed. São Paulo: Cortez, 2001.

NÓVOA, António. Os professores e a sua formação. Portugal: Dom Quixote, 1995.

OLIVEIRA, Zilma Ramos de. Educação Infantil: fundamentos e métodos. São Paulo: Cortez, 2002.

Daniela Gureski Rodrigues cursa especialização em Educação Ambiental, com ênfase em espaços educadores e sustentáveis na Universidade Federal do Paraná (UFPR), Curitiba, Paraná, Brasil.

dany_gureski@yahoo.com.br

Daniele Saheb, doutora em Educação pela Universidade Federal do Paraná (UFPR), é professora da Pontifícia Universidade Católica do Paraná (PUCPR). Membro do grupo de pesquisa Educação, Meio Ambiente e Sociedade da UFPR, Curitiba, Paraná, Brasil.

dansaheb@yahoo.com.br

Recebido em 28 de maio de 2014.

Solicitação de correções em 19 de novembro de 2014.

Aprovado em 27 de novembro de 2014. 